\title{
Predicting Japanese Kampo formulas by analyzing database of medical records: a preliminary observational study
}

Tetsuhiro Yoshino ${ }^{1}$, Kotoe Katayama ${ }^{2}$, Yuko Horiba ${ }^{1}$, Kaori Munakata ${ }^{3}$, Rui Yamaguchi ${ }^{2}$, Seiya Imoto ${ }^{4}$, Satoru Miyano ${ }^{2}$, Hideki Mima ${ }^{5}$ and Kenji Watanabe ${ }^{1,6^{*}}$

\begin{abstract}
Background: Approximately $90 \%$ of physicians in Japan use Kampo medicine in daily practice. However, it is a challenge for physicians who do not specialize in Kampo medicine to select a proper Kampo formula out of the 148 officially approved formulas, as the decision relies on traditional measurements and traditional medicine pattern diagnoses. The present study tries to evaluate the feasibility of a decision support system for frequently used Kampo formulas.

Methods: Our study included 393 patients who visited the Kampo Clinic at Keio University Hospital for the first time between May 2008 and March 2013. We collected medical records through a browser-based questionnaire system and applied random forests to predict commonly prescribed Kampo formulas.

Results: The discriminant rate was the highest (87.0 \%) when we tried to predict a Kampo formula from two candidates using age, sex, body mass index, subjective symptoms, and the two essential and predictable traditional medicine pattern diagnoses (excess-deficiency and heat-cold) as predictor variables. The discriminant rate decreased as the candidate Kampo formulas increased, with the greatest drop occurring between three (76.7 \%) and four (47. $5 \%)$ candidates. Age, body mass index, and traditional medicine pattern diagnoses had higher importance according to the characteristics of each Kampo formula when we utilized the prediction model, which predicted a Kampo formula from among three candidates.
\end{abstract}

Conclusions: These results suggest that our decision support system for non-specialist physicians works well in selecting appropriate Kampo formulas from among two or three candidates. Additional studies are required to integrate the present statistical analysis in clinical practice.

Keywords: Japanese Kampo medicine, Traditional medicine pattern diagnosis, Random forests, Decision support system

\section{Background}

The Japanese national health insurance system covers 148 Kampo formulas-which are traditional Japanese herbal formulas mainly derived from ancient China-making them widely available, and each formula has some indications for Western diseases and/or symptoms. Approximately $90 \%$ of Japanese physicians who learned Western medicine use Kampo formulas in daily practice $[1,2]$. However, in medical

\footnotetext{
* Correspondence: watanabekenji@keio.jp

${ }^{1}$ Center for Kampo Medicine, Keio University School of Medicine, 35

Shinanomachi, Shinjuku-ku, Tokyo 160-8582, Japan

${ }^{6}$ Faculty of Environment and Information Studies, Keio University, 5322 Endo,

Fujisawa, Kanagawa 252-0882, Japan

Full list of author information is available at the end of the article
}

school or continuing medical education, medical students and physicians have limited exposure to Kampo medical education. Thus, it is difficult for most Japanese physicians who do not specialize in Kampo medicine to prescribe Kampo formulas according to the traditional medicine pattern diagnoses and theories of Kampo medicine, which are far different from those of Western medicine. Therefore, the Japanese nonspecialist physicians prescribe Kampo formulas according to the indications based on Western diseases and/or symptoms (i.e., maoto for influenza, yokukansan for dementia, and shakuyakukanzoto for muscle cramps [3-7]). This "Western disease based" prescription of Kampo formula is easy to perform for non-specialist physicians but far different from the 
original way of prescription based on the pattern diagnoses. For example, patients diagnosed with a certain Western disease may have various subjective symptoms and objective findings, and will be classified by pattern diagnoses in Kampo medicine. Moreover, different Kampo formulas can be prescribed for patients with the same pattern diagnosis. Questions about safety, effectiveness, and cost of "Western disease based" prescription of Kampo medicine still remain.

A pattern diagnosis in Kampo medicine refers to the complete clinical presentation of the patient at a given moment in time. Physicians specialized in Kampo medicine use four methods of procedures to make their diagnoses including: inspection, hearing, enquiry, and palpation. Based on the information obtained through these complex procedures, the diagnoses are formed through the process of applying the differential diagnoses for "disharmony symptoms" in the areas of excess-deficiency, heat-cold, and body constituents (Qi, blood, and fluid) to chronic health conditions [8]. However, because there are many ingredients of Kampo formulas and countless traditional medicine pattern diagnoses, it is difficult for non-specialist physicians to accurately and promptly choose a suitable Kampo formula. In this situation, a decision support system (DSS) is required for non-specialist physicians.

We are developing a DSS for non-specialist physicians based on a clinical database created by specialist physicians. This system does not rely on traditional measurement methods such as inspection, hearing, and palpation (including pulse and abdominal examinations), which are difficult for non-specialist physicians to perform. Our DSS comprises two parts: (1) the prediction of the traditional medicine pattern diagnosis, and (2) the prediction of the appropriate Kampo formula. We have already reported on the first part, including the two essential diagnoses-excess-deficiency pattern [9] and heat-cold pattern [10]. However, the second part has not yet been reported on. When the non-specialist physicians can select the appropriate Kampo formula with our DSS, the formula selection will be more safe, efficient, and cost-effective. The standardized and reproducible formula selection will be used for the clinical trials of Kampo medicine which include the idea of pattern diagnoses and proper Kampo formulas.

Herein, we discuss the preliminary results on the use of the DSS for predicting Japanese Kampo formulas for non-specialist physicians.

\section{Methods}

\section{Patient enrollment}

Keio University first introduced a browser-based questionnaire for collecting clinical information in May 2008. The present observational study included patients who made their first visit to the Kampo Clinic at Keio University Hospital between May 2008 and March 2013.
Inclusion criteria were a willingness to be in the study and having more than 20 subjective symptoms as determined by 128 questions in the browser-based questionnaire. We excluded patients who answered "yes" to less than 20 symptoms because they tended to be outliers in our previous research [9]. The participants had to be taking at least one Kampo formula, but not more than two.

Exclusion criteria were missing data on age, sex, body mass index (BMI), subjective symptoms, traditional measurements, information on Western diagnoses, and traditional medicine pattern diagnoses, as well as not being prescribed a Kampo formula. Actually, data collection of BMI was started from January 2012, and most of patients who made their first visit until December 2011 were excluded.

\section{Data collection}

The browser-based questionnaire collected clinical information about patient's subjective symptoms and symptom severity via visual analogue scales (VAS), along with information on age, sex, BMI, traditional measurements, Western diagnoses based on the International Statistical Classification of Diseases and Related Health Problems (ICD-10), traditional medicine pattern diagnoses, and Kampo formulas prescribed by Kampo specialists. We collected information about patients' subjective symptoms using a questionnaire comprising 128 binary questions [11]. You can find all the items in Appendix: Tables 4 and 5. Among these questions, 106 were also assessed using a VAS if patients answered with "yes" to the binary portion. To normalize within each patient, we divided each patient's VAS score by the maximum VAS possible. Data from each question on the traditional measurements, Western diagnoses, traditional medicine pattern diagnoses, and Kampo formulas were binary.

\section{Model fitting procedure}

We applied random forests in accordance with our previous reports $[9,10]$ to predict the frequently used Kampo formulas. Kampo formula for each data record was based on the browser-based questionnaire, and was selected by a Kampo specialist at the first consultation for the patient in Keio University. The random forests method was developed by Breiman $[12,13]$ and is a classification algorithm that uses an ensemble of classification trees. Random forests build a large collection of decorrelated trees and then averages them [14]. Random forests often have very good predictive accuracy [15] and have been widely used in many fields (e.g., body pose recognition for Microsoft's popular Kinect sensor [16]).

We set the number of candidate Kampo formulas from among the most frequent two or more. If there were Kampo formulas with the same frequency, we added either one or all of them as candidates. 
We used two sets of predictor variables: the nonspecialist variable set and the specialist variable set. In this analysis, we did not perform the variable selection. We intended to validate the difference in discriminant rates between these two variable sets to see if the nonspecialist variable set, which did not include all of the items Kampo specialists use in selecting a proper Kampo formula, was appropriate for selecting Kampo formulas. The non-specialist variable set included age, sex, BMI, subjective symptoms, and the two essential and predictable traditional medicine pattern diagnoses-excess-deficiency and heat-cold-according to Kampo specialists. The specialist variable set included ten abdominal examination findings, which are especially important traditional measurement methods, and eight body constituent patterns, in addition to all of the predictor variables of the non-specialist variable set $[8,17]$.

The two essential patterns of the non-specialist variable set were used because we found that they can be accurately predicted using BMI and subjective symptoms $[9,10]$. In contrast, the body constituent patterns were included only in the specialist variable set because they are rather difficult to predict. Abdominal examination findings were also included only in the specialist variable set because it is difficult for non-specialist physicians to perform abdominal examinations without training in Kampo medicine. Furthermore, the findings of abdominal examinations using the traditional method have been reported to vary between observers [18].

An internal validation of the prediction model was based on leave-one-out cross-validation (LOOCV) [19]. In this procedure, we set one patient's data as validation set and the remaining data as training set. For example about the two candidates, hachimijiogan (54 patients) and kamishoyosan (46 patients), we obtained the prediction model for the Kampo formulas with 99 training data, and predicted Kampo formulas for rest one validation data. We calculated the discriminant rate repeating this procedure for all the 100 data. We did not perform any external validation in this preliminary analysis.

\section{Variable importance and the marginal effects of random forests}

Random forests can calculate the mean decrease in the Gini coefficient of each tree. This is called the importance. At each split in each tree, the improvement in the split criterion is an indicator of the importance attributed to the splitting variable; this importance is accumulated over all the trees in the forest separately for each variable. A higher importance means that the variable makes a more sizable contribution to predicting the Kampo formulas.

Random forests also calculate the marginal effect of a variable on the class probability, called the partial dependency. A positive value means that the variable contributes positively to selection of a Kampo formula. In contrast, a negative value indicates that the variable contributes negatively to selection of the Kampo formula. Finally, a value of zero indicates that the variable does not contribute at all to the selection of the Kampo formula.

\section{Statistical analyses}

All statistical analyses were conducted with the use of $\mathrm{R}$ version 3.1.1 (The R Foundation for Statistical Computing; July 10, 2014, see also: http://www.r-project.org). We used the package "randomForest" [20] and parameters were used as default settings. Data are presented as means \pm standard deviations (SDs).

\section{Results \\ Participant information}

We registered 4057 patients who made their first visit to the Kampo Clinic at Keio University Hospital between May 2008 and March 2013. The largest reason of ineligibility was missing data on BMI, which was happened for 2776 patients $(75.8 \%)$ who made their first visit until December 2011. About a half of patients had 19 or fewer subjective symptoms, and about one third of patients were prescribed two or more Kampo formulas. Finally, we decided to use data from 393 patients in this analysis, including 57 male and 336 (85.5 \%) female (Fig. 1). The mean age was $57.9 \pm 16.3$ years old, and the mean BMI was $21.5 \pm$

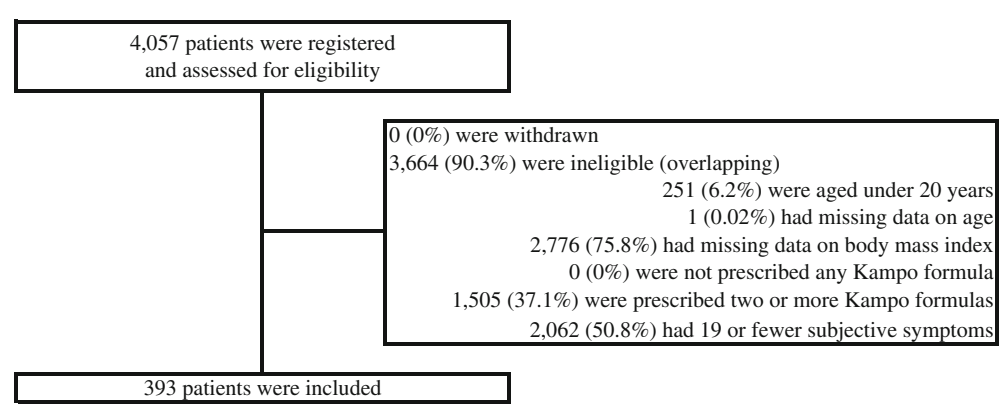

Fig. 1 Participant recruitment flow diagram. The largest cause of ineligibility was missing data of on body mass index, which was happened for 2776 patients (75.8 \%) who made their first visit between May 2008 and December 2011 . Actually, data collection of body mass index was started from January 2012, and most of patients who made their first visit until December 2011 were excluded 
$3.3 \mathrm{~kg} / \mathrm{m}^{2}$. Of the 393 patients, 17 were categorized as showing an excess pattern, 55 a slight excess pattern, 189 an intermediate (between excess and deficiency) pattern, 79 a slight deficiency pattern, and 53 a deficiency pattern. Furthermore, of the total sample, 16 were categorized as showing a heat pattern, 52 an intermediate (neither heat nor cold) pattern, 214 a cold pattern, and 111 a tangled heat and cold (both heat and cold) pattern (Table 1).

Hachimijiogan was the most frequently prescribed Kampo formula (for 54 patients) in our data set, followed by kamishoyosan (46 patients), keishikaryukotsuboreito (33 patients), and keishibukuryogan (29 patients). Shimbuto, bukuryoingohangekobokuto, and yokukansan were each used for 17 patients. We summarized the top 10 frequently used Kampo formulas in Table 2. The mean age for patients prescribed hachimijiogan was the highest of the ten Kampo formulas, and the mean BMI for patients prescribed keishikaryukotsuboreito was the lowest of the ten formulas.

\section{Model fitting procedure}

We applied random forests for the prediction of Kampo formulas from the selected candidates using either the nonspecialist or specialist variable set. The discriminant rate via LOOCV was highest when we tried to predict a Kampo formula from among two candidates, hachimijiogan and kamishoyosan (Fig. 2). The discriminant rate decreased as the number of candidate Kampo formulas increased; in particular, it showed a marked drop in shifting from three to four candidates, meaning when we added the fourth Kampo formula keishibukuryogan to the top three formulas, hachimijiogan, kamishoyosan, and keishikaryukotsuboreito (see also Table 2).

The discriminant rates were 4 to $11.7 \%$ higher when we used the specialist variable set than when using the non-specialist variable set. This gap was smallest when we tried to predict Kampo formulas from among two candidates.

\section{Variable importance and marginal effects from random forests}

Non-specialists would appear to benefit from having fewer candidates when selecting Kampo formulas. In addition, the discriminant rate dropped considerably when the number of candidate Kampo formulas reached four as noted in the previous section. As such, for the non-specialist variable set, we selected a prediction model wherein Kampo formulas were predicted from among three candidates. We then analyzed how this model worked with our data set.

Among the top 30 items in terms of importance, we found that age and BMI had the highest and second highest values, respectively (Table 3). Here, we focused on the top 10 variables with higher importance, and analyzed how they worked in this model. Figure 3 shows the partial dependency plot about the top 10 important variables in
Table 1 Baseline characteristics of participants

\begin{tabular}{|c|c|c|}
\hline & Eligible patients & Ineligible patients \\
\hline Number of patients & 393 & 3664 \\
\hline \multicolumn{3}{|l|}{ Age at consultation } \\
\hline Mean \pm SD & $57.9 \pm 16.3$ & $46.2 \pm 19.5$ \\
\hline Median (Range) & $61(20-91)$ & $44(0-95)$ \\
\hline N/A (\%) & $0(0)$ & $1(0.03)$ \\
\hline Male: Female & $57: 336$ & 1073:2591 \\
\hline \multicolumn{3}{|l|}{$\mathrm{BMI}, \mathrm{kg} / \mathrm{m}^{2}$} \\
\hline Mean \pm SD & $21.5 \pm 3.3$ & $21.0 \pm 3.5$ \\
\hline Median (Range) & $21.1(12.8-35.2)$ & $21.0(12.1-43.9)$ \\
\hline N/A (\%) & $0(0)$ & $2776(75.8)$ \\
\hline \multicolumn{3}{|l|}{ Number of subjective symptoms } \\
\hline Mean \pm SD & $32.1 \pm 10.2$ & $21.0 \pm 12.8$ \\
\hline Median (Range) & $30(20-93)$ & $18(1-99)$ \\
\hline N/A (\%) & $0(0)$ & $19(0.5)$ \\
\hline \multicolumn{3}{|c|}{ Chief complaints (Top 10 in eligible patients) } \\
\hline Cold sensations & $72(18.3)$ & $455(12.4)$ \\
\hline Insomnia & 69 (17.6) & $259(7.1)$ \\
\hline Hypertension & $62(15.8)$ & $230(6.3)$ \\
\hline Constipation & $42(10.7)$ & $199(5.4)$ \\
\hline Dyslipidemia & $36(9.2)$ & $61(1.7)$ \\
\hline Depression & $29(7.4)$ & $76(2.1)$ \\
\hline Dizziness & $27(6.9)$ & $69(1.9)$ \\
\hline Chronic gastritis & $26(6.6)$ & $102(2.8)$ \\
\hline Tinnitus & $24(6.1)$ & $76(2.1)$ \\
\hline Headache & $22(5.6)$ & $166(4.5)$ \\
\hline \multicolumn{3}{|l|}{ Excess-Deficiency pattern (\%) } \\
\hline Excess pattern & $17(4.3)$ & $276(7.5)$ \\
\hline Slight excess pattern & $55(14.0)$ & $396(10.8)$ \\
\hline $\begin{array}{l}\text { Intermediate (between excess } \\
\text { and deficiency) pattern }\end{array}$ & $189(48.1)$ & $1933(52.8)$ \\
\hline Slight deficiency pattern & $79(20.1)$ & $546(14.9)$ \\
\hline Deficiency pattern & $53(13.5)$ & $513(14.0)$ \\
\hline \multicolumn{3}{|l|}{ Heat-Cold pattern (\%) } \\
\hline Heat pattern & $16(4.1)$ & $210(5.7)$ \\
\hline $\begin{array}{l}\text { Intermediate (neither heat nor } \\
\text { cold) pattern }\end{array}$ & $52(13.2)$ & $1234(33.7)$ \\
\hline Cold pattern & $214(54.5)$ & $1574(43.0)$ \\
\hline $\begin{array}{l}\text { Tangled heat and cold (both } \\
\text { heat and cold) pattern }\end{array}$ & $111(28.2)$ & $313(8.5)$ \\
\hline
\end{tabular}

Table 3. For example, in the upper left plot for age and BMI, the solid line indicates that those with an age of greater than 60 and a BMI over 20 had a positive value for hachimijiogan. In other words, the model suggests that hachimijiogan be selected when the patients are older 
Table 2 Demographics and standard traditional pattern diagnosis of frequently used Kampo formulas

\begin{tabular}{|c|c|c|c|c|c|c|c|}
\hline & Number & Mean age $\pm S D$ & Male: Female & Mean $\mathrm{BMI} \pm \mathrm{SD}$ & Excess-Deficiency & Heat-Cold & $\begin{array}{l}\text { Body constituent } \\
\text { (Qi-Blood-Fluid) }\end{array}$ \\
\hline Hachimijiogan & 54 & $71.9 \pm 9.6$ & 19:35 & $22.9 \pm 3.1$ & Deficiency & Cold & Fluid disturbance \\
\hline Kamishoyosan & 46 & $53.5 \pm 13.3$ & $0: 46$ & $22.2 \pm 2.4$ & Deficiency & $\begin{array}{l}\text { Tangled heat } \\
\text { and cold }\end{array}$ & $\begin{array}{l}\text { Qi counterflow } \\
\text { Blood stasis }\end{array}$ \\
\hline Keishikaryukotsuboreito & 33 & $56.3 \pm 14.1$ & $2: 31$ & $18.6 \pm 2.2$ & Deficiency & Intermediate & Qi counterflow \\
\hline Keishibukuryogan & 29 & $49.0 \pm 15.1$ & $0: 29$ & $23.2 \pm 3.4$ & Intermediate & Intermediate & $\begin{array}{l}\text { Qi counterflow } \\
\text { Blood stasis }\end{array}$ \\
\hline Shimbuto & 17 & $62.4 \pm 18.4$ & 2:15 & $20.2 \pm 4.0$ & Deficiency & Cold & Fluid disturbance \\
\hline Bukuryoingohangekobokuto & 17 & $55.6 \pm 14.3$ & $1: 16$ & $20.7 \pm 3.6$ & Deficiency & Intermediate & $\begin{array}{l}\text { Qi stagnation } \\
\text { Fluid disturbance }\end{array}$ \\
\hline Yokukansan & 17 & $51.9 \pm 16.0$ & $2: 15$ & $21.3 \pm 2.6$ & Intermediate & Heat & Not defined \\
\hline Tokishakuyakusan & 15 & $49.1 \pm 16.4$ & $0: 15$ & $20.2 \pm 1.5$ & Deficiency & Cold & $\begin{array}{l}\text { Blood stasis } \\
\text { Fluid disturbance }\end{array}$ \\
\hline Hochuekkito & 12 & $60.6 \pm 16.1$ & $2: 10$ & $22.0 \pm 2.7$ & Deficiency & Intermediate & Qi deficiency \\
\hline Tokishigyakukagoshuyushokyoto & 11 & $58.1 \pm 13.7$ & $0: 11$ & $22.6 \pm 3.0$ & Deficiency & Cold & Not defined \\
\hline Overall & 393 & $57.9 \pm 16.3$ & $56: 337$ & $21.5 \pm 3.3$ & & & \\
\hline
\end{tabular}

Abbreviations: $B M I$ body mass index, SD Standard deviation

than 60 and have a BMI over 20. In contrast, the model suggests that hachimijiogan is not as suitable when the patients are younger than 60 and have a BMI under 20. Similarly, an age under 60 and a BMI over 20 suggests that kamishoyosan be selected, while a BMI under 20

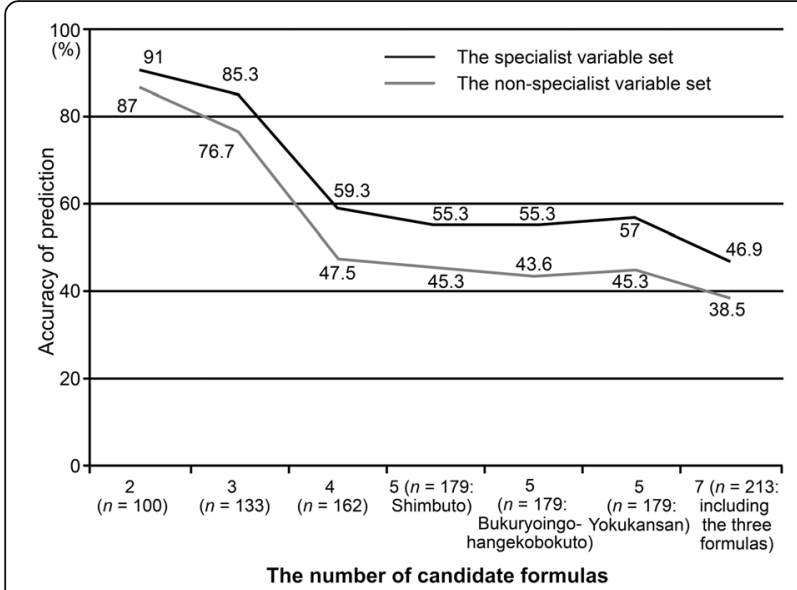

Fig. 2 Leave-one-out cross-validation accuracy of prediction according to the number of candidate Kampo formulas. The discriminant rate via leave-one-out cross-validation was highest when we tried to predict a Kampo formula from among two candidates, hachimijiogan and kamishoyosan. The discriminant rate decreased as the number of candidate Kampo formulas increased; in particular, it showed a marked drop in shifting from three to four candidates, meaning when we added the fourth Kampo formula keishibukuryogan to the top three formulas, hachimijiogan, kamishoyosan, and keishikaryukotsuboreito (see also Table 2). The non-specialist variable set included age, sex, body mass index, and subjective symptoms, as well as the two essential and predictable traditional medicine pattern diagnoses (excess-deficiency and heat-cold) according to Kampo specialists. The specialist variable set included abdominal examination findings and body constituent patterns in addition to all of the predictor variables of the non-specialist variable set indicates the selection of keishikaryukotsuboreito. The partial dependency of age for keishikaryukotsuboreito was consistently negative, meaning that all ages contributed negatively to selection of this Kampo formula, especially ages over 60 (Fig. 3; age and BMI). These findings indicate that an age of around 60 and a BMI of around 20 did not contribute to the selection of Kampo formulas, except for negatively affecting selection of keishikaryukotsuboreito. These findings on the partial dependency of age and BMI were consistent with the characteristics of patients prescribed the three Kampo formulas shown in Table 2.

We also found that the two traditional medicine pattern diagnoses, excess-deficiency and heat-cold, had high importance (Table 3). The partial dependency plot for excess-deficiency patterns showed that the deficiency pattern indicated use of keishikaryukotsuboreito and not hachimijiogan. In contrast, the excess pattern suggested the use of hachimijiogan or kamishoyosan and not keishikaryukotsuboreito (Fig. 3; excess-deficiency pattern). In fact, Kampo specialists rarely prescribed hachimijiogan for treating patients diagnosed with a deficiency or a slight deficiency pattern. In contrast, keishikaryukotsuboreito was not prescribed for patients diagnosed with a slight excess pattern or an excess pattern (Fig. 4). The partial dependency plot for the heat pattern showed that the heat pattern indicated the use of kamishoyosan, and not hachimijiogan or keishikaryukotsuboreito (Fig. 3; heat pattern). Patients who were diagnosed with a heat pattern or a tangled heat and cold pattern by Kampo specialists were generally not prescribed hachimijiogan. In contrast, over $60 \%$ of patients who were prescribed kamishoyosan were diagnosed as having a heat pattern or a tangled heat and cold pattern (Fig. 5). 
Table 3 Top 30 most important variables for predicting top 3 Kampo formulas with non-specialist variable set. Higher importance values indicate that the item makes a more sizable contribution to predicting the Kampo formulas

\begin{tabular}{|c|c|c|}
\hline No. & Item name & Importance \\
\hline 1 & Age & 6.96 \\
\hline 2 & Body mass index & 5.78 \\
\hline 3 & Excess-deficiency pattern & 4.92 \\
\hline 4 & Depressed mood & 2.17 \\
\hline 5 & Irritability & 2.07 \\
\hline 6 & Early-morning awakening & 2.00 \\
\hline 7 & Heat sensation in the face & 1.98 \\
\hline 8 & Hot flashes & 1.96 \\
\hline 9 & Heat pattern & 1.95 \\
\hline 10 & Neck stiffness & 1.73 \\
\hline 11 & Sex & 1.57 \\
\hline 12 & Bleary eyes & 1.57 \\
\hline 13 & Palpitations & 1.50 \\
\hline 14 & Tires easily & 1.49 \\
\hline 15 & Eyestrain & 1.40 \\
\hline 16 & Leg fluctuation & 1.29 \\
\hline 17 & Arousal during sleep & 1.22 \\
\hline 18 & Headache & 1.21 \\
\hline 19 & Difficulty in falling asleep & 1.21 \\
\hline 20 & Shoulder stiffness & 1.20 \\
\hline 21 & Leg spasms & 1.08 \\
\hline 22 & Forgetfulness & 1.06 \\
\hline 23 & Shoulder pain & 1.00 \\
\hline 24 & Hie legs & 0.89 \\
\hline 25 & Quick to sweat & 0.89 \\
\hline 26 & Back stiffness & 0.87 \\
\hline 27 & Decreased visual acuity & 0.86 \\
\hline 28 & Sleepy after eating & 0.85 \\
\hline 29 & Numbness legs & 0.82 \\
\hline 30 & Dry skin & 0.81 \\
\hline
\end{tabular}

In a similar manner with the subjective symptoms, lack of depressed mood and irritability; early-morning awakening; and lack of heat sensation in the face, hot flashes, or neck stiffness indicated the use of hachimijiogan. In contrast, presence of depressed mood and irritability; lack of earlymorning awakening; and presence of hot flashes, heat sensation in the face, and neck stiffness indicated the use of kamishoyosan. Lack of irritability and hot flashes and the presence of a depressed mood and early-morning awakening indicated the use of keishikaryukotsuboreito (Fig. 3; depressed mood, irritability, early-morning awakening, heat sensation in the face, hot flashes, and neck stiffness). This was consistent with the results related to the severity of symptoms summarized in Fig. 6. Many of the patients who were prescribed hachimijiogan did not have a depressed mood, irritability, heat sensation in the face, or hot flashes. They also tended not to have neck stiffness. In contrast, many patients who were prescribed kamishoyosan exhibited a depressed mood, irritability, heat sensation in the face, and hot flashes, but did not exhibit early-morning awakening. Patients who were prescribed keishikaryukotsuboreito tended to exhibit a more depressed mood and early-morning awakening and to not exhibit irritability or hot flashes.

To further understanding, we provided the results from multinomial logistic regression when we tried to predict a Kampo formula from among the same three candidates with using non-specialist variable set in Appendix: Tables 4 and 5 . You can obtain area under the receiver operating characteristic curves, and crude odds ratios with $95 \%$ confidential intervals for each item of non-specialist variable set.

\section{Discussion}

Approximately $90 \%$ of Japanese physicians who are well educated in Western medicine use Kampo formulas regularly despite not having specific education in Kampo medicine. We believe that they will benefit most from the DSS to make more standardized traditional medicine pattern diagnoses and prescribe appropriate Kampo formulas [2]. In this article, we discussed the preliminary results of our DSS in predicting use of appropriate Kampo formulas.

In this study, we used only $9.7 \%$ of overall patients' data. Although it is uncommon, we provided the baseline characteristics of participants not only about eligible patients but also ineligible patients. Our data were primarily obtained from female patients, and this sex difference is common in Japanese Kampo clinics [21, 22]. This is because some Kampo formulas, including kamishoyosan and keishibukuryogan, are especially used for female patients. These Kampo formulas are originally designed for perimenopausal or postpartum women, respectively. We could obtain similar results using only data from female patients. When we excluded male patients, female sex was disappeared from the table of important variables but the other variables had almost the same rank with same value of importance (Data not shown).

Our results suggested that a greater number of candidate Kampo formulas led to a worse discriminant rate. Specifically, the DSS could only handle around two or three frequently used Kampo formulas, even though there are far more officially approved formulas in Kampo medicine. Indeed, upon including a fourth Kampo formula, keishibukuryogan, the discriminant rate dropped by approximately $30 \%$. This was likely because it was difficult to differentiate between the second Kampo formula, kamishoyosan, and the fourth, keishibukuryogan (data not shown). Our data suggest that differences between the top three Kampo formulas were rather large, whereas the differences between 


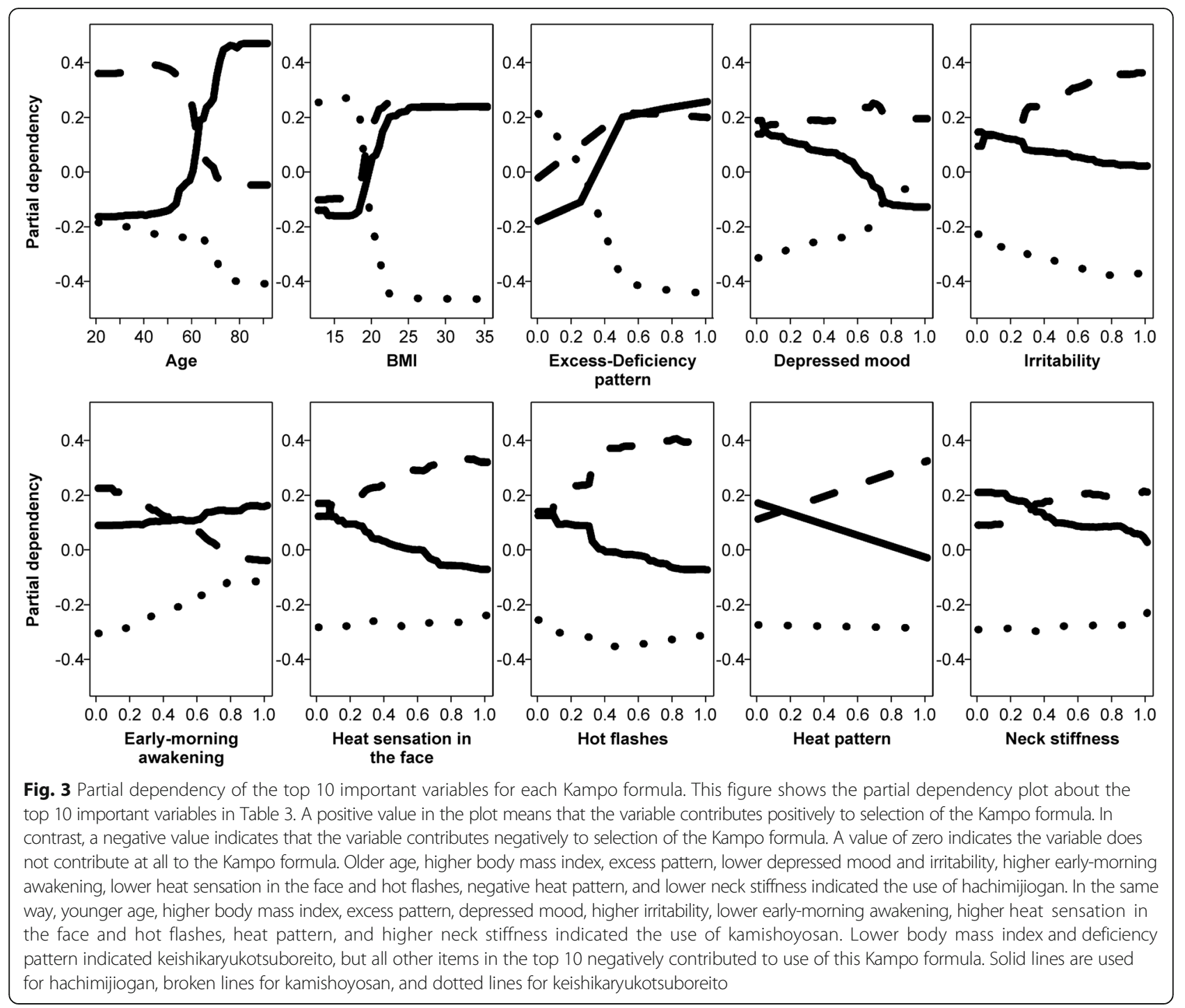

these top three formulas and the more minor formulas were relatively small. If our DSS could handle only these two or three candidate Kampo formulas, it would not be able to support non-specialist physicians in daily practice.

Our DSS might be able to cover more Kampo formulas using cluster analysis, which has already given us other candidate formulas [23]. Our DSS will support non-specialist physicians in daily practice when the DSS will be combined with the cluster analysis. We have already reported that cluster analysis can reproduce some traditional medicine pattern diagnoses, and that frequently used Kampo formulas differed among each cluster, in accordance with the traditional medicine pattern diagnoses they best suited [23]. In other words, our model can be applied to different clusters of diagnoses, which may help us obtain the most appropriate Kampo formulas from among those most frequently used. However, there are only a few papers reporting the results of a cluster analysis on this topic.
Ishizuka et al. also reported on the results of a cluster analysis of patients who visited a Kampo institution in Japan. They concluded that their cluster analysis results supported the rationale behind the empirical determination of traditional medicine pattern diagnosis [24]. However, their results supported only kidney and liver deficiency patterns, and did not discuss Kampo formulas. There are two more articles reporting cluster analyses, but they are not widely accessible because they are written in Chinese $[25,26]$.

We utilized two sets of predictor variables, and found that the non-specialist variable set worked well in predicting appropriate Kampo formulas. Indeed, the discriminant rates were more affected by the number of candidate Kampo formulas than by the change in the variable set. We found that we could achieve higher discriminant rates when we used the specialist variable set including the abdominal examination findings and the body constituent patterns. However, the findings from traditional measurements can 


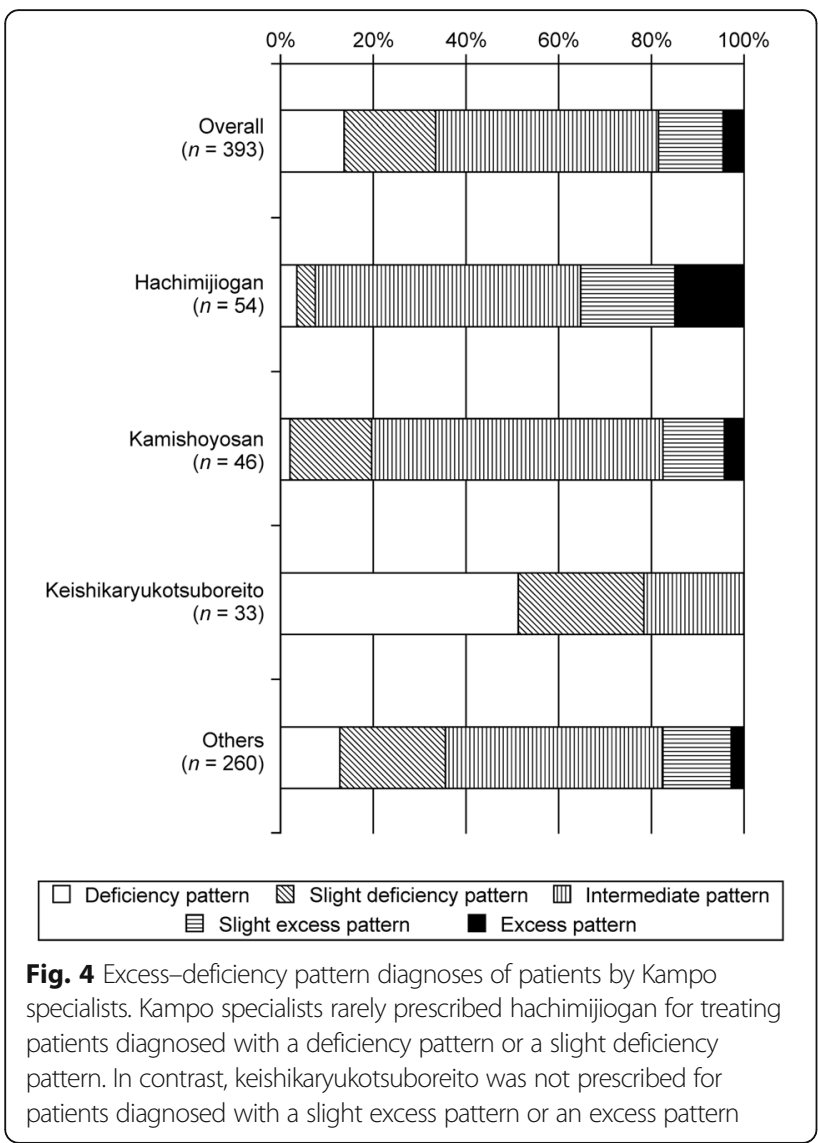

vary between physicians, and thus the standardization of such traditional measurements remains an issue [27]. Use of standardized traditional measurements will help also in the prediction of body constituent patterns.

We analyzed the importance and partial dependency of the variables. It must be noted that the variables with high importance are useful only for the random forests and would not directly relate to the clinical decisions of Kampo specialists. However, we noted that many of these items were compatible with our clinical experience. While this experience is based on ancient knowledge and traditional theory, a significant amount of it has proven relevant today. For example, Odaguchi et al., in 2007, reported that a Kampo formula, goshuyuto, was effective for some patients with headaches with specific characteristics; these characteristics were similar to those written about in traditional medical textbooks [28].

We also tried using logistic regression with Lasso penalty as a linear model [29] and classification and regression trees (CART) as a non-linear model [30], but random forests performed the best in terms of the discriminant rate. For example, the discriminant rates were 85.0 and $79.0 \%$ by logistic regression, or by CART, respectively, when we tried to predict a Kampo formula from among two candidates with nonspecialist variable set. In contrast, the discriminant rates via LOOCV were both $90.0 \%$ with specialist variable set by

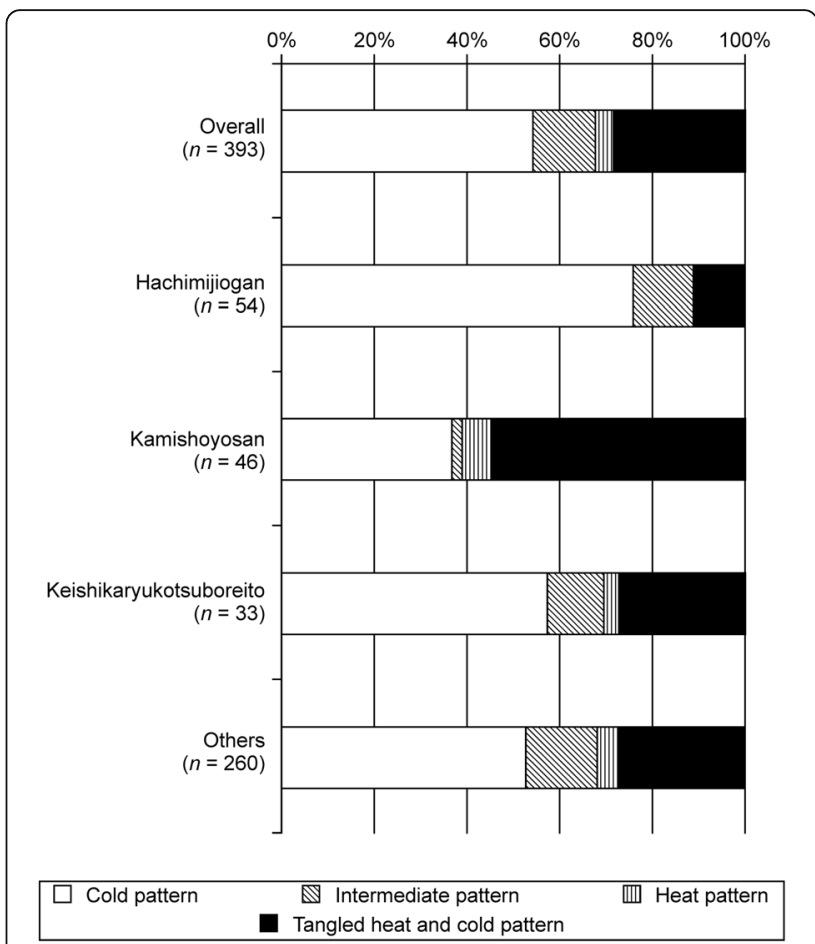

Fig. 5 Heat-cold pattern diagnoses of patients by Kampo specialists. Patients who were diagnosed with a heat pattern or a tangled heat and cold pattern by Kampo specialists were rare among patients who were prescribed hachimijiogan. In contrast, over $60 \%$ of patients who were prescribed kamishoyosan were diagnosed with a heat pattern or a tangled heat and cold pattern

logistic regression methods, or by CART. From this result, the statistical methods are not important issue with enough predictors, but are important with restricted predictors.

Herein, we predicted specialists' selections of Kampo formulas in daily clinical situations, and the selection didn't depend on an objective golden standard or pre-defined standards. The Kampo specialists select a "proper" Kampo formula based on traditional medicine pattern diagnosis and theory. We provided the standard pattern diagnosis for each Kampo formula defined by the Japanese Society of Oriental Medicine in Table 2. However, the diagnosis in the table was not the only one way, and different pattern diagnosis can be made for the patients with the same Kampo formulas as shown in the Figs. 4 and 5. We can understand the actual connection between Kampo formula and traditional medicine pattern diagnosis with this study, but we can also recognize a problem about standardization of diagnosis and Kampo formula selection. One possible reason of this discrepancy is the indications for each Kampo formula do not include traditional medicine pattern diagnosis; rather they rely only on Western diseases and symptoms.

Additionally, we did not consider efficacy. "True" Kampo formulas must be defined by their efficacy. Although most prescriptions by specialists are effective, sometimes there 


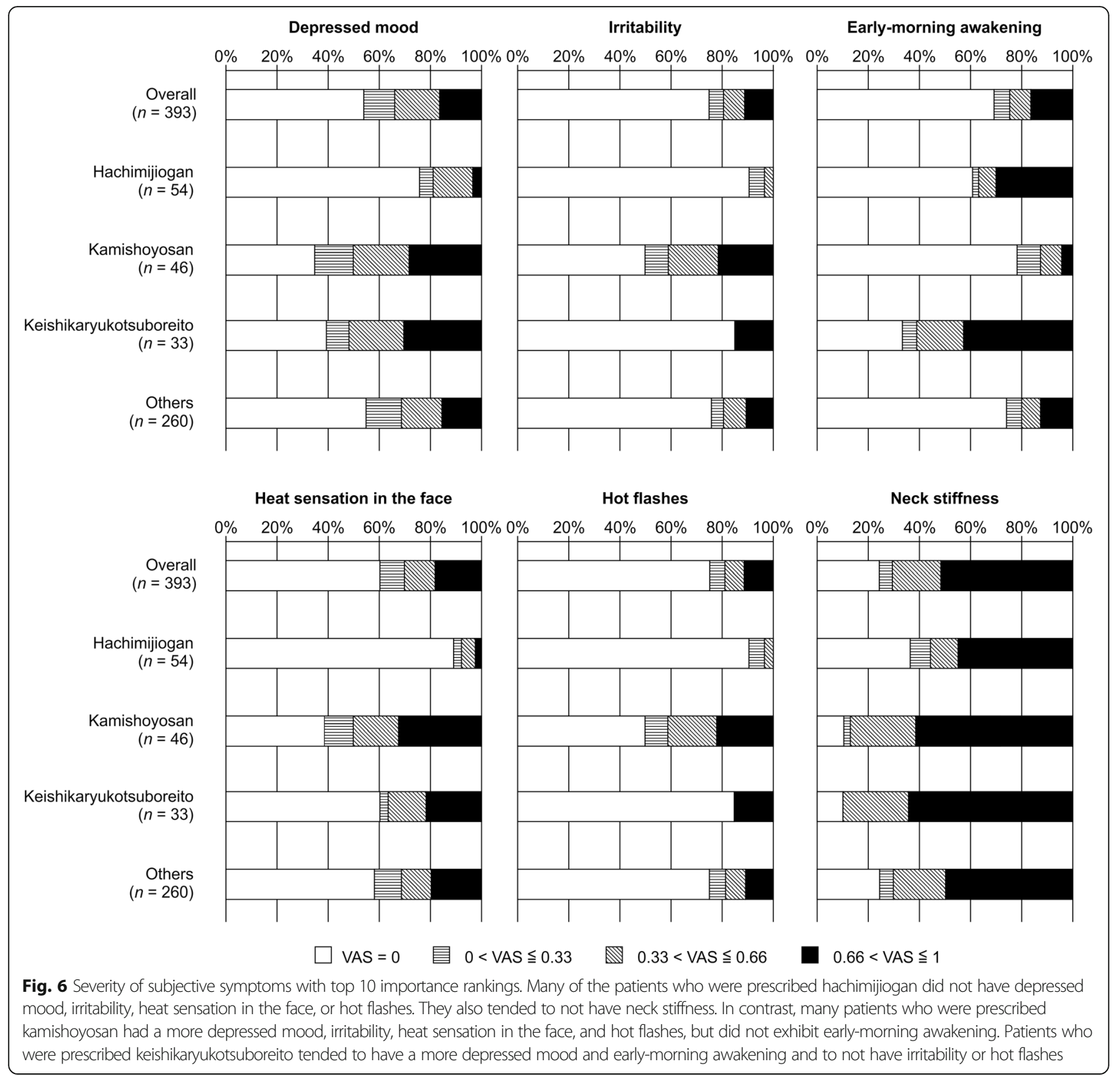

may be better options. We have already noticed that a few patients got better after changing the Kampo formula which was selected at the first consultation. Then, we must carefully confirm the proper Kampo formula, especially for patients whose formulas were difficult to predict.

We did not perform variable selection in this analysis, and used many variables for small number of patients. The prediction models with small number of variables may be better for generalization like applying this method to other medical record databases. We, however, showed the results with all of the potential variables because we thought it would help non-specialist physicians to understand specialists' tacit knowledge (See also Appendix: Tables 4 and 5).
Our aim is to further progress this DSS reflecting clinical outcomes and the experience of other institutions. Now, we are collecting clinical information through the browser-based questionnaire at some representative institutions about Kampo medicine. We have collected more than forty thousand of record from more than eight thousand patients. This data will further progress our DSS.

\section{Conclusions}

Our decision support system for non-specialist physicians works well in selecting a proper Kampo formula from two or three candidates. Additional studies are required to integrate such statistical analysis in clinical practice. 


\section{Appendix}

Table 4 Area under the receiver operating characteristic curve for each combination of formulas. Area under the curve (AUC) was calculated using the R package "pROC". A value of 1 for the dependent variable (case) denotes the Kampo formula listed in the upper row. A value of 0 for the dependent variable (control) denotes the Kampo formula listed in the bottom row. AUC > 0.5 indicates preferential use of the Case Kampo formula when the patient gave a positive response (or relatively higher response in the case of visual analogue scales) for each item. In contrast, AUC $<0.5$ indicates use of the Control Kampo formula when the patient gave a positive response. Items with AUC values over 0.7 or under 0.3 are shown in bold, indicating strongly suggestive results. Item names with (Bi) means binary questions, and without (Bi) means questions with visual analogue scales

\begin{tabular}{|c|c|c|c|}
\hline \multirow{2}{*}{$\begin{array}{l}\text { Item name } \\
1 \text { (case) } \\
0 \text { (control) }\end{array}$} & \multicolumn{3}{|c|}{ Area under the curve } \\
\hline & $\begin{array}{l}\text { Hachimijiogan vs } \\
\text { Kamishoyosan }\end{array}$ & $\begin{array}{l}\text { Kamishoyosan vs } \\
\text { Keishikaryukotsuboreito }\end{array}$ & $\begin{array}{l}\text { Hachimijiogan vs } \\
\text { Keishikaryukotsuboreito }\end{array}$ \\
\hline \multicolumn{4}{|l|}{ Subjective symptoms } \\
\hline \multicolumn{4}{|l|}{ Appetite } \\
\hline Appetite loss (Bi) & 0.506 & 0.355 & 0.361 \\
\hline Good appetite (Bi) & 0.521 & 0.513 & 0.535 \\
\hline \multicolumn{4}{|l|}{ Speed of the meal } \\
\hline Slow speed of the meal (Bi) & 0.515 & 0.496 & 0.511 \\
\hline Fast speed of the meal (Bi) & 0.502 & 0.518 & 0.520 \\
\hline Difficulty falling asleep & 0.610 & 0.319 & 0.442 \\
\hline Arousal during sleep & 0.562 & 0.307 & 0.372 \\
\hline Early-morning awakening & 0.611 & 0.242 & 0.385 \\
\hline I dream frequently (Bi) & 0.424 & 0.429 & 0.353 \\
\hline Single dose of urine large (Bi) & 0.497 & 0.507 & 0.503 \\
\hline Single dose of urine low (Bi) & 0.555 & 0.474 & 0.529 \\
\hline Difficulty urinating & 0.554 & 0.511 & 0.565 \\
\hline Urination pain & 0.509 & 0.500 & 0.509 \\
\hline Urine leakage & 0.484 & 0.573 & 0.552 \\
\hline Enuresis & 0.500 & 0.500 & 0.500 \\
\hline Hard stool (Bi) & 0.490 & 0.535 & 0.525 \\
\hline Small and round stool (Bi) & 0.400 & 0.568 & 0.468 \\
\hline Soft stool (Bi) & 0.442 & 0.475 & 0.417 \\
\hline Diarrhea & 0.490 & 0.456 & 0.446 \\
\hline Hard to stool (Bi) & 0.546 & 0.489 & 0.535 \\
\hline Hemorrhoid & 0.486 & 0.484 & 0.474 \\
\hline Anal prolapse & 0.528 & 0.485 & 0.513 \\
\hline Bloody stool & 0.489 & 0.496 & 0.485 \\
\hline Taking laxatives (Bi) & 0.527 & 0.505 & 0.532 \\
\hline Depressed mood & 0.267 & 0.491 & 0.291 \\
\hline Forgetfullness & 0.488 & 0.403 & 0.393 \\
\hline Irritated & 0.287 & 0.698 & 0.496 \\
\hline Dry skin & 0.391 & 0.527 & 0.428 \\
\hline Itchy skin & 0.508 & 0.544 & 0.564 \\
\hline Acne & 0.457 & 0.513 & 0.470 \\
\hline Blot & 0.378 & 0.524 & 0.405 \\
\hline Urticaria & 0.442 & 0.561 & 0.505 \\
\hline Wart & 0.484 & 0.498 & 0.482 \\
\hline Athlete's foot & 0.542 & 0.522 & 0.566 \\
\hline
\end{tabular}


Table 4 Area under the receiver operating characteristic curve for each combination of formulas. Area under the curve (AUC) was calculated using the R package "pROC". A value of 1 for the dependent variable (case) denotes the Kampo formula listed in the upper row. A value of 0 for the dependent variable (control) denotes the Kampo formula listed in the bottom row. AUC $>0.5$ indicates preferential use of the Case Kampo formula when the patient gave a positive response (or relatively higher response in the case of visual analogue scales) for each item. In contrast, $A U C<0.5$ indicates use of the Control Kampo formula when the patient gave a positive response. Items with AUC values over 0.7 or under 0.3 are shown in bold, indicating strongly suggestive results. Item names with (Bi) means binary questions, and without (Bi) means questions with visual analogue scales (Continued)

\begin{tabular}{|c|c|c|c|}
\hline Brittle nails & 0.415 & 0.541 & 0.458 \\
\hline Get tired easily & 0.359 & 0.439 & 0.296 \\
\hline Easy to sweat & 0.364 & 0.573 & 0.449 \\
\hline Night sweats & 0.477 & 0.503 & 0.479 \\
\hline Hot flush & 0.286 & 0.648 & 0.464 \\
\hline Heat intolerance & 0.426 & 0.580 & 0.522 \\
\hline Cold intolerance & 0.497 & 0.427 & 0.428 \\
\hline Attenuation of sexual desire & 0.505 & 0.447 & 0.449 \\
\hline Impotence (male) & 0.519 & 0.485 & 0.504 \\
\hline Neck stiffness & 0.353 & 0.484 & 0.356 \\
\hline Shoulder stiffness & 0.402 & 0.438 & 0.362 \\
\hline Back stiffness & 0.464 & 0.418 & 0.401 \\
\hline Lower back stiffness & 0.469 & 0.470 & 0.440 \\
\hline Facial pain & 0.500 & 0.485 & 0.485 \\
\hline Hand pain & 0.504 & 0.459 & 0.462 \\
\hline Foot pain & 0.605 & 0.455 & 0.562 \\
\hline Shoulder pain & 0.452 & 0.445 & 0.405 \\
\hline Back pain & 0.481 & 0.501 & 0.482 \\
\hline Hip pain & 0.593 & 0.498 & 0.586 \\
\hline Knee pain & 0.595 & 0.564 & 0.648 \\
\hline Numbness face & 0.478 & 0.477 & 0.455 \\
\hline Numbness hands & 0.538 & 0.489 & 0.531 \\
\hline Numbness legs & 0.615 & 0.501 & 0.617 \\
\hline Numbness back & 0.498 & 0.481 & 0.478 \\
\hline Trembling face & 0.489 & 0.511 & 0.500 \\
\hline Trembling hands & 0.513 & 0.447 & 0.461 \\
\hline Trembling legs & 0.478 & 0.507 & 0.485 \\
\hline Hie general & 0.452 & 0.529 & 0.482 \\
\hline Hie hands & 0.465 & 0.439 & 0.403 \\
\hline Hie legs & 0.550 & 0.459 & 0.491 \\
\hline Hie lower back & 0.520 & 0.460 & 0.482 \\
\hline Heat face & 0.240 & 0.595 & 0.348 \\
\hline Heat hands & 0.446 & 0.539 & 0.485 \\
\hline Heat legs & 0.455 & 0.540 & 0.494 \\
\hline Edema face & 0.454 & 0.565 & 0.513 \\
\hline Edema hands & 0.464 & 0.570 & 0.531 \\
\hline Edema legs & 0.458 & 0.534 & 0.495 \\
\hline Headache & 0.357 & 0.604 & 0.457 \\
\hline Sluggishness & 0.405 & 0.482 & 0.400 \\
\hline Vertigo & 0.480 & 0.495 & 0.477 \\
\hline
\end{tabular}


Table 4 Area under the receiver operating characteristic curve for each combination of formulas. Area under the curve (AUC) was calculated using the R package "pROC". A value of 1 for the dependent variable (case) denotes the Kampo formula listed in the upper row. A value of 0 for the dependent variable (control) denotes the Kampo formula listed in the bottom row. AUC $>0.5$ indicates preferential use of the Case Kampo formula when the patient gave a positive response (or relatively higher response in the case of visual analogue scales) for each item. In contrast, AUC $<0.5$ indicates use of the Control Kampo formula when the patient gave a positive response. Items with AUC values over 0.7 or under 0.3 are shown in bold, indicating strongly suggestive results. Item names with (Bi) means binary questions, and without (Bi) means questions with visual analogue scales (Continued)

\begin{tabular}{|c|c|c|c|}
\hline Lightheadedness & 0.432 & 0.514 & 0.452 \\
\hline Dandruff & 0.544 & 0.466 & 0.510 \\
\hline Hair loss & 0.430 & 0.522 & 0.449 \\
\hline Decreased visual acuity & 0.457 & 0.492 & 0.455 \\
\hline Eyestrain & 0.338 & 0.549 & 0.401 \\
\hline Blurred vision & 0.442 & 0.559 & 0.500 \\
\hline Bleary eyes & 0.298 & 0.604 & 0.411 \\
\hline Dark circles of the eyes & 0.407 & 0.512 & 0.425 \\
\hline Sneezing & 0.497 & 0.560 & 0.555 \\
\hline White nasal discharge (Bi) & 0.467 & 0.477 & 0.444 \\
\hline Yellow nasal discharge (Bi) & 0.508 & 0.511 & 0.519 \\
\hline Post nasal drip & 0.496 & 0.426 & 0.418 \\
\hline Stuffy nose & 0.533 & 0.445 & 0.477 \\
\hline Nosebleed & 0.489 & 0.481 & 0.470 \\
\hline Mouth bitter & 0.490 & 0.468 & 0.457 \\
\hline Saliva comes out & 0.488 & 0.522 & 0.509 \\
\hline Throat pain & 0.482 & 0.482 & 0.464 \\
\hline Throat jams & 0.395 & 0.583 & 0.481 \\
\hline Thirsty & 0.529 & 0.493 & 0.523 \\
\hline Dry mouth & 0.456 & 0.461 & 0.420 \\
\hline Dry lips & 0.496 & 0.423 & 0.413 \\
\hline Take water often & 0.468 & 0.522 & 0.496 \\
\hline Tinnitus & 0.491 & 0.536 & 0.527 \\
\hline Hearing loss & 0.637 & 0.481 & 0.618 \\
\hline Cough & 0.477 & 0.509 & 0.485 \\
\hline White sputum (Bi) & 0.562 & 0.431 & 0.492 \\
\hline Yellow sputum (Bi) & 0.517 & 0.481 & 0.497 \\
\hline Asthma & 0.476 & 0.533 & 0.509 \\
\hline Shortness of breath & 0.512 & 0.417 & 0.428 \\
\hline Palpitation & 0.368 & 0.414 & 0.280 \\
\hline Chest pain & 0.503 & 0.466 & 0.470 \\
\hline Burp & 0.429 & 0.525 & 0.457 \\
\hline Heartburn & 0.508 & 0.522 & 0.533 \\
\hline Epigastric jamming discomfort & 0.494 & 0.451 & 0.445 \\
\hline Nausea & 0.477 & 0.469 & 0.448 \\
\hline Vomiting & 0.500 & 0.485 & 0.485 \\
\hline Motion sickness & 0.489 & 0.508 & 0.500 \\
\hline Stomach fullness & 0.498 & 0.518 & 0.513 \\
\hline Stomach rumbling & 0.476 & 0.408 & 0.386 \\
\hline Flaturence & 0.537 & 0.507 & 0.547 \\
\hline
\end{tabular}


Table 4 Area under the receiver operating characteristic curve for each combination of formulas. Area under the curve (AUC) was calculated using the R package "pROC". A value of 1 for the dependent variable (case) denotes the Kampo formula listed in the upper row. A value of 0 for the dependent variable (control) denotes the Kampo formula listed in the bottom row. AUC $>0.5$ indicates preferential use of the Case Kampo formula when the patient gave a positive response (or relatively higher response in the case of visual analogue scales) for each item. In contrast, $A U C<0.5$ indicates use of the Control Kampo formula when the patient gave a positive response. Items with AUC values over 0.7 or under 0.3 are shown in bold, indicating strongly suggestive results. Item names with (Bi) means binary questions, and without (Bi) means questions with visual analogue scales (Continued)

\begin{tabular}{|c|c|c|c|}
\hline Sleepy after eating & 0.393 & 0.587 & 0.481 \\
\hline Abdominal pain & 0.525 & 0.409 & 0.438 \\
\hline Abdominal pain fasting (Bi) & 0.519 & 0.455 & 0.473 \\
\hline Abdominal pain after eating (Bi) & 0.509 & 0.455 & 0.464 \\
\hline Abdominal pain at upper (Bi) & 0.500 & 0.470 & 0.470 \\
\hline Abdominal pain at lower (Bi) & 0.526 & 0.465 & 0.492 \\
\hline Hand stiffness & 0.460 & 0.556 & 0.513 \\
\hline Lower extremities weakness & 0.589 & 0.450 & 0.543 \\
\hline Legs fluctuates & 0.669 & 0.466 & 0.637 \\
\hline Leg spasms & 0.598 & 0.541 & 0.655 \\
\hline Frost bite & 0.487 & 0.517 & 0.504 \\
\hline Heavy menstrual flow (Female, Bi) & 0.435 & 0.565 & 0.500 \\
\hline Less menstrual flow (Female, Bi) & 0.435 & 0.489 & 0.424 \\
\hline Menstruation textile (Female) & 0.370 & 0.533 & 0.409 \\
\hline Menstrual pain (Female) & 0.359 & 0.586 & 0.439 \\
\hline Irregular menstruation (Female, Bi) & 0.402 & 0.507 & 0.409 \\
\hline Delivery (Female, Bi) & 0.466 & 0.460 & 0.426 \\
\hline Spontaneous abortion (Female, Bi) & 0.458 & 0.537 & 0.495 \\
\hline Induced abortion (Female, Bi) & 0.514 & 0.472 & 0.486 \\
\hline Pregnancy toxemia (Female, Bi) & 0.498 & 0.496 & 0.494 \\
\hline Abnormal bleeding (Female, Bi) & 0.478 & 0.507 & 0.485 \\
\hline \multicolumn{4}{|l|}{ Traditional pattern diagnosis } \\
\hline Excess-Deficiency pattern (Five categories) & 0.624 & 0.856 & 0.899 \\
\hline Cold pattern (Bi) & 0.479 & 0.532 & 0.511 \\
\hline Heat pattern (Bi) & 0.251 & 0.653 & 0.404 \\
\hline \multicolumn{4}{|l|}{ Background } \\
\hline Female sex (Bi) & 0.324 & 0.530 & 0.354 \\
\hline Age & 0.861 & 0.422 & 0.839 \\
\hline Body mass index & 0.589 & 0.878 & 0.887 \\
\hline
\end{tabular}


Table 5 Crude odds ratios for each combination of Kampo formulas. To measure the effect size of each predictive variable, we performed multinomial logistic regression. Odds ratio (OR) was calculated using the R package "nnet". A value of 1 for the dependent variable (case) denotes the Kampo formula listed in the upper row. A value of 0 for the dependent variable (control) denotes the Kampo formula listed in the bottom row. Item names with (Bi) means binary questions, and without (Bi) means questions with visual analogue scales

\begin{tabular}{|c|c|c|c|}
\hline \multirow{2}{*}{$\begin{array}{l}\text { Item name } \\
1 \text { (case) } \\
0 \text { (control) } \\
\end{array}$} & \multicolumn{3}{|c|}{ Crude odds ratio (95 \% confidence intervals) } \\
\hline & $\begin{array}{l}\text { Hachimijiogan vs } \\
\text { Kamishoyosan }\end{array}$ & $\begin{array}{l}\text { Kamishoyosan vs } \\
\text { Keishikaryukotsuboreito }\end{array}$ & $\begin{array}{l}\text { Hachimijiogan vs } \\
\text { Keishikaryukotsuboreito }\end{array}$ \\
\hline \multicolumn{4}{|l|}{ Subjective symptoms } \\
\hline \multicolumn{4}{|l|}{ Appetite } \\
\hline Appetite loss (Bi) & $1.294(0.207,8.099)$ & $0.091(0.019,0.446)$ & $0.118(0.030,0.463)$ \\
\hline Good appetite (Bi) & $1.564(0.427,5.722)$ & $1.476(0.254,8.578)$ & $2.309(0.450,11.848)$ \\
\hline \multicolumn{4}{|l|}{ Speed of the meal } \\
\hline Slow speed of the meal (Bi) & $1.215(0.443,3.336)$ & $0.947(0.295,3.046)$ & $1.151(0.381,3.476)$ \\
\hline Fast speed of the meal (Bi) & $1.028(0.398,2.659)$ & $1.250(0.404,3.864)$ & $1.286(0.431,3.835)$ \\
\hline Difficulty falling asleep & $3.755(1.231,11.453)$ & $0.175(0.052,0.591)$ & $0.657(0.234,1.844)$ \\
\hline Arousal during sleep & $1.912(0.663,5.517)$ & $0.158(0.049,0.510)$ & $0.302(0.104,0.882)$ \\
\hline Early-morning awakening & $6.605(1.708,25.547)$ & $0.051(0.012,0.218)$ & $0.340(0.117,0.991)$ \\
\hline I dream frequently (Bi) & $0.378(0.136,1.050)$ & $0.535(0.208,1.372)$ & $0.202(0.071,0.579)$ \\
\hline Single dose of urine large (Bi) & $0.846(0.114,6.256)$ & $1.455(0.126,16.743)$ & $1.231(0.107,14.128)$ \\
\hline Single dose of urine low (Bi) & $2.114(0.732,6.107)$ & $0.675(0.197,2.315)$ & $1.427(0.483,4.212)$ \\
\hline Difficulty urinating & $14.328(0.269,762.157)$ & $62249680000.000(0.000, \operatorname{lnf})$ & $1029688000000.000(0.000$, Inf $)$ \\
\hline Urination pain & $13075.100(0.000, \operatorname{lnf})$ & $0.049(0.000, \ln f)$ & $428.912(0.000, \operatorname{lnf})$ \\
\hline Urine leakage & $2.761(0.258,29.497)$ & $8.399(0.143,492.448)$ & $23.184(0.463,1161.637)$ \\
\hline Enuresis & $1.000(1.000,1.000)$ & $1.000(1.000,1.000)$ & $1.000(1.000,1.000)$ \\
\hline Hard stool (Bi) & $0.833(0.249,2.786)$ & $2.325(0.439,12.321)$ & $1.938(0.367,10.219)$ \\
\hline Small and round stool (Bi) & $0.326(0.124,0.856)$ & $1.981(0.706,5.559)$ & $0.646(0.210,1.985)$ \\
\hline Soft stool (Bi) & $0.508(0.194,1.328)$ & $0.788(0.299,2.073)$ & $0.400(0.145,1.107)$ \\
\hline Diarrhea & $0.664(0.055,8.056)$ & $0.308(0.032,2.974)$ & $0.204(0.020,2.116)$ \\
\hline Hard to stool (Bi) & $1.905(0.652,5.561)$ & $0.840(0.233,3.025)$ & $1.600(0.508,5.041)$ \\
\hline Hemorrhoid & $2.321(0.191,28.221)$ & $0.313(0.022,4.417)$ & $0.726(0.078,6.721)$ \\
\hline Anal prolapse & $63127200000.000(0.000, \operatorname{lnf})$ & $0.000(0.000, \operatorname{lnf})$ & $10.162(0.019,5537.952)$ \\
\hline Bloody stool & $0.000(0.000, \ln f)$ & $1.265(0.016,97.879)$ & $0.000(0.000, \operatorname{lnf})$ \\
\hline Taking laxatives (Bi) & $1.515(0.505,4.547)$ & $1.087(0.281,4.205)$ & $1.648(0.472,5.755)$ \\
\hline Depressed mood & $0.048(0.010,0.225)$ & $0.836(0.215,3.248)$ & $0.040(0.008,0.208)$ \\
\hline Forgetfullness & $0.816(0.184,3.615)$ & $0.237(0.049,1.132)$ & $0.193(0.042,0.895)$ \\
\hline Irritated & $0.076(0.018,0.318)$ & $10.981(2.154,55.976)$ & $0.834(0.151,4.604)$ \\
\hline Dry skin & $0.330(0.103,1.062)$ & $1.259(0.364,4.346)$ & $0.416(0.115,1.498)$ \\
\hline Itchy skin & $0.951(0.294,3.082)$ & $1.612(0.401,6.488)$ & $1.534(0.396,5.946)$ \\
\hline Acne & $0.000(0.000, \operatorname{lnf})$ & $1.581(0.036,68.993)$ & $0.000(0.000, \operatorname{lnf})$ \\
\hline Blot & $0.276(0.080,0.958)$ & $1.240(0.358,4.300)$ & $0.343(0.088,1.333)$ \\
\hline Urticaria & $0.154(0.020,1.157)$ & $3.170(0.415,24.193)$ & $0.488(0.043,5.517)$ \\
\hline Wart & $0.508(0.052,4.934)$ & $0.960(0.102,9.032)$ & $0.488(0.043,5.562)$ \\
\hline Athlete's foot & $1.611(0.171,15.202)$ & $1.042(0.067,16.120)$ & $1.678(0.135,20.941)$ \\
\hline Brittle nails & $0.312(0.089,1.103)$ & $1.561(0.417,5.838)$ & $0.488(0.119,2.004)$ \\
\hline Get tired easily & $0.250(0.084,0.738)$ & $0.519(0.135,1.994)$ & $0.129(0.035,0.475)$ \\
\hline Easy to sweat & $0.256(0.086,0.763)$ & $1.847(0.583,5.856)$ & $0.472(0.140,1.598)$ \\
\hline
\end{tabular}


Table 5 Crude odds ratios for each combination of Kampo formulas. To measure the effect size of each predictive variable, we performed multinomial logistic regression. Odds ratio (OR) was calculated using the R package "nnet". A value of 1 for the dependent variable (case) denotes the Kampo formula listed in the upper row. A value of 0 for the dependent variable (control) denotes the Kampo formula listed in the bottom row. Item names with (Bi) means binary questions, and without (Bi) means questions with visual analogue scales (Continued)

\begin{tabular}{|c|c|c|c|}
\hline Night sweats & $0.367(0.053,2.539)$ & $1.416(0.194,10.350)$ & $0.520(0.059,4.598)$ \\
\hline Hot flush & $0.022(0.003,0.182)$ & $4.207(1.003,17.643)$ & $0.091(0.009,0.896)$ \\
\hline Heat intolerance & $0.348(0.110,1.106)$ & $2.768(0.729,10.504)$ & $0.964(0.243,3.825)$ \\
\hline Cold intolerance & $0.951(0.364,2.483)$ & $0.527(0.180,1.545)$ & $0.501(0.177,1.423)$ \\
\hline Attenuation of sexual desire & $0.807(0.078,8.353)$ & $0.222(0.030,1.624)$ & $0.179(0.024,1.327)$ \\
\hline Impotence (male) & $10052440000.000(0.000, \ln f)$ & $0.000(0.000, \ln f)$ & $8.044(0.030,2144.688)$ \\
\hline Neck stiffness & $0.220(0.074,0.652)$ & $1.142(0.321,4.066)$ & $0.251(0.077,0.823)$ \\
\hline Shoulder stiffness & $0.356(0.119,1.062)$ & $0.671(0.175,2.563)$ & $0.239(0.067,0.852)$ \\
\hline Back stiffness & $0.695(0.250,1.932)$ & $0.539(0.177,1.645)$ & $0.375(0.125,1.127)$ \\
\hline Lower back stiffness & $0.798(0.290,2.195)$ & $0.743(0.244,2.258)$ & $0.592(0.199,1.763)$ \\
\hline Facial pain & $0.077(0.000, \ln f)$ & $0.001(0.000, \ln f)$ & $0.001(0.000, \operatorname{lnf})$ \\
\hline Hand pain & $1.879(0.276,12.784)$ & $0.201(0.030,1.366)$ & $0.378(0.074,1.932)$ \\
\hline Foot pain & $6.765(1.390,32.926)$ & $0.374(0.060,2.339)$ & $2.529(0.615,10.389)$ \\
\hline Shoulder pain & $0.360(0.086,1.504)$ & $0.497(0.142,1.746)$ & $0.179(0.043,0.754)$ \\
\hline Back pain & $0.590(0.102,3.413)$ & $0.734(0.132,4.071)$ & $0.433(0.071,2.641)$ \\
\hline Hip pain & $2.550(0.930,6.989)$ & $0.863(0.264,2.825)$ & $2.200(0.732,6.607)$ \\
\hline Knee pain & $4.040(0.981,16.643)$ & $2.473(0.326,18.786)$ & $9.990(1.516,65.813)$ \\
\hline Numbness face & $0.000(0.000, \ln f)$ & $0.480(0.039,5.954)$ & $0.000(0.000, \operatorname{lnf})$ \\
\hline Numbness hands & $1.681(0.457,6.179)$ & $1.257(0.253,6.243)$ & $2.113(0.470,9.493)$ \\
\hline Numbness legs & $4.200(1.272,13.868)$ & $1.025(0.224,4.683)$ & $4.304(1.116,16.605)$ \\
\hline Numbness back & $0.166(0.001,21.502)$ & $0.393(0.024,6.450)$ & $0.065(0.001,7.255)$ \\
\hline Trembling face & $0.000(0.000, \ln f)$ & $6455194000000.000(0.000$, Inf $)$ & $0.000(0.000, \operatorname{lnf})$ \\
\hline Trembling hands & $2.850(0.152,53.518)$ & $0.083(0.005,1.464)$ & $0.236(0.024,2.331)$ \\
\hline Trembling legs & $0.000(0.000, \ln f)$ & $21.730(0.011,43198.600)$ & $0.000(0.000, \ln f)$ \\
\hline Hie general & $0.531(0.169,1.668)$ & $1.439(0.407,5.079)$ & $0.764(0.206,2.830)$ \\
\hline Hie hands & $0.522(0.141,1.931)$ & $0.557(0.159,1.947)$ & $0.291(0.077,1.098)$ \\
\hline Hie legs & $1.683(0.630,4.492)$ & $0.623(0.204,1.903)$ & $1.049(0.352,3.123)$ \\
\hline Hie lower back & $1.474(0.358,6.075)$ & $0.550(0.118,2.562)$ & $0.811(0.200,3.291)$ \\
\hline Heat face & $0.021(0.004,0.121)$ & $2.401(0.724,7.959)$ & $0.049(0.008,0.311)$ \\
\hline Heat hands & $0.000(0.000, \ln f)$ & $5.293(0.280,99.894)$ & $0.000(0.000, \operatorname{lnf})$ \\
\hline Heat legs & $0.166(0.013,2.050)$ & $12.968(0.202,831.143)$ & $2.150(0.023,205.044)$ \\
\hline Edema face & $0.698(0.141,3.450)$ & $4.373(0.392,48.772)$ & $3.053(0.271,34.455)$ \\
\hline Edema hands & $0.920(0.126,6.713)$ & $9.190(0.226,373.346)$ & $8.452(0.215,332.751)$ \\
\hline Edema legs & $0.691(0.246,1.937)$ & $1.388(0.429,4.491)$ & $0.959(0.300,3.061)$ \\
\hline Headache & $0.132(0.032,0.545)$ & $3.796(0.856,16.839)$ & $0.501(0.096,2.605)$ \\
\hline Sluggishness & $0.176(0.033,0.943)$ & $0.700(0.171,2.868)$ & $0.123(0.022,0.701)$ \\
\hline Vertigo & $0.747(0.206,2.707)$ & $0.938(0.229,3.832)$ & $0.701(0.173,2.839)$ \\
\hline Lightheadedness & $0.403(0.085,1.906)$ & $0.960(0.198,4.648)$ & $0.387(0.072,2.066)$ \\
\hline Dandruff & $94.688(0.100,89677.910)$ & $0.008(0.000,9.612)$ & $0.826(0.038,17.818)$ \\
\hline Hair loss & $0.286(0.069,1.187)$ & $1.316(0.328,5.280)$ & $0.376(0.078,1.804)$ \\
\hline Decreased visual acuity & $0.603(0.194,1.877)$ & $0.779(0.228,2.667)$ & $0.470(0.138,1.604)$ \\
\hline Eyestrain & $0.215(0.074,0.627)$ & $1.754(0.540,5.702)$ & $0.377(0.119,1.189)$ \\
\hline
\end{tabular}


Table 5 Crude odds ratios for each combination of Kampo formulas. To measure the effect size of each predictive variable, we performed multinomial logistic regression. Odds ratio (OR) was calculated using the R package "nnet". A value of 1 for the dependent variable (case) denotes the Kampo formula listed in the upper row. A value of 0 for the dependent variable (control) denotes the Kampo formula listed in the bottom row. Item names with (Bi) means binary questions, and without (Bi) means questions with visual analogue scales (Continued)

\begin{tabular}{|c|c|c|c|}
\hline Blurred vision & $0.616(0.203,1.867)$ & $1.718(0.477,6.183)$ & $1.058(0.295,3.794)$ \\
\hline Bleary eyes & $0.110(0.033,0.367)$ & $2.698(0.789,9.228)$ & $0.297(0.080,1.102)$ \\
\hline Dark circles of the eyes & $0.206(0.049,0.862)$ & $1.207(0.344,4.235)$ & $0.248(0.053,1.161)$ \\
\hline Sneezing & $0.712(0.162,3.126)$ & $3.991(0.505,31.530)$ & $2.840(0.361,22.364)$ \\
\hline White nasal discharge (Bi) & $0.612(0.208,1.799)$ & $0.760(0.258,2.236)$ & $0.465(0.151,1.433)$ \\
\hline Yellow nasal discharge (Bi) & $1.732(0.152,19.747)$ & $1712.672(0.000, \operatorname{lnf})$ & $2964.441(0.000, \mathrm{Inf})$ \\
\hline Post nasal drip & $0.934(0.197,4.425)$ & $0.404(0.086,1.897)$ & $0.377(0.084,1.691)$ \\
\hline Stuffy nose & $2.178(0.511,9.288)$ & $0.374(0.078,1.807)$ & $0.815(0.207,3.217)$ \\
\hline Nosebleed & $0.000(0.000, \operatorname{lnf})$ & $0.152(0.001,29.264)$ & $0.000(0.000, \operatorname{lnf})$ \\
\hline Mouth bitter & $0.536(0.073,3.919)$ & $0.770(0.111,5.315)$ & $0.413(0.052,3.257)$ \\
\hline Saliva comes out & $0.316(0.007,15.076)$ & $86710.230(0.000, \mathrm{lnf})$ & $27731.080(0.000$, Inf $)$ \\
\hline Throat pain & $0.721(0.165,3.142)$ & $0.873(0.181,4.223)$ & $0.630(0.130,3.057)$ \\
\hline Throat jams & $0.029(0.002,0.499)$ & $4.805(0.583,39.619)$ & $0.141(0.006,3.387)$ \\
\hline Thirsty & $1.197(0.377,3.801)$ & $0.960(0.255,3.613)$ & $1.149(0.323,4.090)$ \\
\hline Dry mouth & $0.557(0.167,1.859)$ & $0.707(0.202,2.478)$ & $0.394(0.110,1.414)$ \\
\hline Dry lips & $0.757(0.189,3.030)$ & $0.450(0.112,1.811)$ & $0.340(0.085,1.365)$ \\
\hline Take water often & $0.624(0.198,1.959)$ & $1.286(0.357,4.636)$ & $0.802(0.223,2.887)$ \\
\hline Tinnitus & $1.023(0.374,2.796)$ & $1.213(0.374,3.933)$ & $1.241(0.397,3.876)$ \\
\hline Hearing loss & $6.628(1.557,28.215)$ & $0.634(0.106,3.811)$ & $4.205(0.970,18.224)$ \\
\hline Cough & $0.323(0.032,3.239)$ & $3.661(0.227,59.010)$ & $1.182(0.063,22.259)$ \\
\hline White sputum (Bi) & $4.398(0.899,21.512)$ & $0.205(0.038,1.087)$ & $0.900(0.288,2.808)$ \\
\hline Yellow sputum (Bi) & $2.647(0.266,26.361)$ & $0.344(0.030,3.966)$ & $0.912(0.144,5.764)$ \\
\hline Asthma & $0.068(0.001,4.411)$ & $687350.400(0.000, \operatorname{lnf})$ & $46587.550(0.000$, Inf $)$ \\
\hline Shortness of breath & $1.714(0.370,7.932)$ & $0.199(0.042,0.948)$ & $0.341(0.086,1.357)$ \\
\hline Palpitation & $0.107(0.021,0.545)$ & $0.437(0.116,1.648)$ & $0.047(0.009,0.254)$ \\
\hline Chest pain & $1.960(0.181,21.196)$ & $0.168(0.016,1.737)$ & $0.329(0.047,2.317)$ \\
\hline Burp & $0.025(0.001,0.949)$ & $1.456(0.237,8.942)$ & $0.037(0.001,1.542)$ \\
\hline Heartburn & $0.857(0.160,4.580)$ & $1.748(0.229,13.308)$ & $1.497(0.203,11.033)$ \\
\hline Epigastric jamming discomfort & $0.889(0.109,7.221)$ & $0.285(0.042,1.940)$ & $0.253(0.039,1.653)$ \\
\hline Nausea & $0.165(0.002,16.148)$ & $0.124(0.007,2.196)$ & $0.021(0.000,1.437)$ \\
\hline Vomiting & $0.007(0.000, \operatorname{lnf})$ & $0.000(0.000, \operatorname{lnf})$ & $0.000(0.000, \operatorname{lnf})$ \\
\hline Motion sickness & $0.498(0.081,3.067)$ & $1.386(0.198,9.705)$ & $0.690(0.086,5.527)$ \\
\hline Stomach fullness & $1.141(0.277,4.691)$ & $0.907(0.181,4.530)$ & $1.034(0.223,4.806)$ \\
\hline Stomach rumbling & $0.647(0.127,3.288)$ & $0.235(0.053,1.044)$ & $0.152(0.033,0.705)$ \\
\hline Flaturence & $1.357(0.452,4.078)$ & $0.963(0.270,3.434)$ & $1.306(0.389,4.385)$ \\
\hline Sleepy after eating & $0.242(0.067,0.881)$ & $2.939(0.704,12.275)$ & $0.712(0.155,3.274)$ \\
\hline Abdominal pain & $4.467(0.333,59.926)$ & $0.080(0.006,1.071)$ & $0.356(0.055,2.285)$ \\
\hline Abdominal pain fasting (Bi) & $4740.774(0.000$, Inf $)$ & $0.000(0.000, \operatorname{lnf})$ & $0.385(0.061,2.434)$ \\
\hline Abdominal pain after eating (Bi) & $524.449(0.000, \mathrm{lnf})$ & $0.000(0.000, \operatorname{lnf})$ & $0.188(0.019,1.892)$ \\
\hline Abdominal pain at upper (Bi) & $0.083(0.000, \operatorname{lnf})$ & $0.000(0.000, \operatorname{lnf})$ & $0.000(0.000, \operatorname{lnf})$ \\
\hline Abdominal pain at lower (Bi) & $3.600(0.388,33.412)$ & $0.222(0.022,2.238)$ & $0.800(0.167,3.822)$ \\
\hline Hand stiffness & $0.650(0.194,2.181)$ & $3.021(0.604,15.108)$ & $1.963(0.388,9.934)$ \\
\hline
\end{tabular}


Table 5 Crude odds ratios for each combination of Kampo formulas. To measure the effect size of each predictive variable, we performed multinomial logistic regression. Odds ratio (OR) was calculated using the R package "nnet". A value of 1 for the dependent variable (case) denotes the Kampo formula listed in the upper row. A value of 0 for the dependent variable (control) denotes the Kampo formula listed in the bottom row. Item names with (Bi) means binary questions, and without (Bi) means questions with visual analogue scales (Continued)

\begin{tabular}{|c|c|c|c|}
\hline Lower extremities weakness & $5.565(1.157,26.752)$ & $0.396(0.064,2.432)$ & $2.201(0.523,9.265)$ \\
\hline Legs fluctuates & $7.336(1.999,26.919)$ & $0.586(0.124,2.765)$ & $4.296(1.136,16.249)$ \\
\hline Leg spasms & $2.550(0.840,7.743)$ & $2.151(0.514,8.998)$ & $5.486(1.402,21.468)$ \\
\hline Frost bite & $1.469(0.098,21.934)$ & $4.616(0.029,735.479)$ & $6.778(0.050,920.821)$ \\
\hline Heavy menstrual flow (Female, Bi) & $0.000(0.000, \ln f)$ & $18125.110(0.000$, Inf $)$ & $0.045(0.000, \operatorname{lnf})$ \\
\hline Less menstrual flow (Female, Bi) & $0.000(0.000, \ln f)$ & $0.840(0.233,3.025)$ & $0.000(0.000, \ln f)$ \\
\hline Menstruation textile (Female) & $0.000(0.000, \ln f)$ & $1.297(0.176,9.535)$ & $0.000(0.000, \ln f)$ \\
\hline Menstrual pain (Female) & $0.000(0.000, \ln f)$ & $4.351(0.811,23.337)$ & $0.000(0.000, \operatorname{lnf})$ \\
\hline Irregular menstruation (Female, Bi) & $0.000(0.000, \ln f)$ & $1.094(0.348,3.442)$ & $0.000(0.000, \ln f)$ \\
\hline Delivery (Female, Bi) & $0.758(0.343,1.675)$ & $0.711(0.280,1.804)$ & $0.538(0.219,1.324)$ \\
\hline Spontaneous abortion (Female, Bi) & $0.514(0.168,1.573)$ & $1.764(0.493,6.306)$ & $0.906(0.236,3.484)$ \\
\hline Induced abortion (Female, Bi) & $1.463(0.330,6.482)$ & $0.506(0.105,2.430)$ & $0.740(0.184,2.978)$ \\
\hline Pregnancy toxemia (Female, Bi) & $0.849(0.052,13.965)$ & $0.711(0.043,11.795)$ & $0.604(0.036,9.992)$ \\
\hline Abnormal bleeding (Female, Bi) & $0.000(0.000, \ln f)$ & $1.445(0.126,16.595)$ & $0.000(0.000, \operatorname{lnf})$ \\
\hline \multicolumn{4}{|l|}{ Traditional pattern diagnosis } \\
\hline Excess-Deficiency pattern (Five categories) & $9.695(1.270,74.040)$ & $1313.121(79.316,21739.580)$ & $12696.900(560.943,287393.200)$ \\
\hline Cold pattern (Bi) & $0.639(0.175,2.340)$ & $1.875(0.463,7.596)$ & $1.199(0.347,4.141)$ \\
\hline Heat pattern (Bi) & $0.080(0.029,0.226)$ & $3.578(1.384,9.247)$ & $0.288(0.093,0.888)$ \\
\hline \multicolumn{4}{|l|}{ Background } \\
\hline Female sex (Bi) & $0.000(0.000, \ln f)$ & $1129.553(0.000$, Inf $)$ & $0.118(0.025,0.549)$ \\
\hline Age & $1.142(1.089,1.197)$ & $0.985(0.953,1.018)$ & $1.125(1.073,1.180)$ \\
\hline Body mass index & $1.092(0.942,1.266)$ & $1.924(1.472,2.516)$ & $2.102(1.600,2.763)$ \\
\hline
\end{tabular}

\section{Abbreviations}

BMl: Body mass index; CART: Classification and regression trees; DSS: Decision support system; ICD-10: International statistical classification of diseases and related health problems 10th revision; LOOCV: Leave-one-out cross-validation; SD: Standard deviations; VAS: Visual analogue scale

\section{Acknowledgements}

We would like to thank Editage for providing editorial assistance. A part of this work was presented at the 10th International Congress on Complementary Medicine Research, Jeju, Republic of Korea.

\section{Funding}

This work was supported by a Grant-in-Aid for Research on Propulsion Study of Clinical Research from the Ministry of Health, Labour and Welfare in building the questionnaire, data collection, and analysis. We would also like to thank NAKATANI foundation for advancement of measuring technologies in biomedical engineering for a travel to the 10th International Congress on Complementary Medicine Research, Jeju, Republic of Korea.

\section{Availability of data and materials}

Specific data on the study will be available from the authors on request.

\section{Authors' contributions}

TY had full access to all of the data in the study and took responsibility for the integrity of the data and the accuracy of data analysis. KK contributed to supervision of the study, review of the data, and writing the manuscript. YH participated to study design; provided comments on the final version of the manuscript. KM participated to study design; provided comments on the final version of the manuscript. RY participated to study design; provided comments on the final version of the manuscript. SI participated to study design; provided comments on the final version of the manuscript. SM participated to study design; provided comments on the final version of the manuscript. HM participated to study design; provided comments on the final version of the manuscript. KW coordinated the study; participated to study design; provided comments on the final version of the manuscript. Other authors contributed to the study supervision. All authors read and approved the final manuscript.

\section{Competing interests}

The authors declare that they have no competing interests.

\section{Consent for publication}

Not applicable.

\section{Ethics approval and consent to participate}

The Institutional Review Board at Keio University School of Medicine approved this study (Approved No. 20100144 and 20140191), and all registered patients provided written or digitally recorded informed consent.

\section{Author details}

${ }^{1}$ Center for Kampo Medicine, Keio University School of Medicine, 35

Shinanomachi, Shinjuku-ku, Tokyo 160-8582, Japan. ${ }^{2}$ Human Genome Center, The Institute of Medical Science, The University of Tokyo, 4-6-1 Shirokanedai, Minato-ku, Tokyo 108-8639, Japan. ${ }^{3}$ SFC Laboratory, Keio University, 5322 Endo, Fujisawa, Kanagawa 252-0882, Japan. ${ }^{4}$ Division of Health Medical Data Science, Health Intelligence Center, The Institute of Medical Science, The 
University of Tokyo, 4-6-1 Shirokanedai, Minato-ku, Tokyo 108-8639, Japan. ${ }^{5}$ School of Engineering, The University of Tokyo, 7-3-1 Hongo, Bunkyo-ku, Tokyo 113-8656, Japan. ${ }^{6}$ Faculty of Environment and Information Studies, Keio University, 5322 Endo, Fujisawa, Kanagawa 252-0882, Japan.

\section{Received: 10 December 2015 Accepted: 6 September 2016}

\section{Published online: 13 September 2016}

\section{References}

1. ON-LINE Survey. Actual use research and consciousness survey on Kampo medicine 2010. Nikkei Med Suppl. 2010;513:38-9.

2. Moschik EC, Mercado C, Yoshino T, Matsuura K, Watanabe K. Usage and attitudes of physicians in Japan concerning traditional Japanese medicine (kampo medicine): a descriptive evaluation of a representative questionnairebased survey. Evid Based Complement Alternat Med. 2012;2012:139818.

3. Kubo T, Nishimura H. Antipyretic effect of Mao-to, a Japanese herbal medicine, for treatment of type A influenza infection in children. Phytomedicine. 2007;14(2-3):96-101.

4. Saita M, Naito T, Boku S, Watanabe $Y$, Suzuki M, Oka F, et al. The efficacy of ma-huang-tang (maoto) against influenza. Health. 2011;3(5):300-3.

5. Nabeshima S, Kashiwagi K, Ajisaka K, Masui S, Takeoka H, Ikematsu H, et al. A randomized, controlled trial comparing traditional herbal medicine and neuraminidase inhibitors in the treatment of seasonal influenza. J Infect Chemother. 2012;18(4):534-43.

6. Matsuda Y, Kishi T, Shibayama H, Iwata N. Yokukansan in the treatment of behavioral and psychological symptoms of dementia: a systematic review and meta-analysis of randomized controlled trials. Hum Psychopharmacol. 2013:28(1):80-6.

7. Kumada T, Kumada H, Yoshiba M, Nakano S, Suzuki H, Tango T. Effects of shakuyaku-kanzo-to (Tsumura TJ-68) on muscle cramps accompanying cirrhosis in a placebo-controlled double-blind parallel study. J Clin Therap Med. 1999;15(3):499-523.

8. Yakubo $S$, Ito M, Ueda $Y$, Okamoto $H$, Kimura $Y$, Amano $Y$, et al. Pattern classification in kampo medicine. Evid Based Complement Alternat Med. 2014:2014:535146.

9. Katayama K, Yamaguchi R, Imoto S, Watanabe K, Miyano S. Analysis of questionnaire for traditional medicine and development of decision support system. Evid Based Complement Alternat Med. 2014;2014:974139.

10. Yoshino T, Katayama K, Munakata K, Horiba Y, Yamaguchi R, Imoto S, et al. Prediction of heat-cold pattern diagnosis. In: 31st Annual Meeting of Medicinal and Pharmaceutical Society for WAKAN-YAKU; Chiba, Japan. 2014

11. Yoshino T, Katayama K, Munakata K, Horiba $Y$, Yamaguchi R, Imoto $S$, Miyano S, Watanabe K. Statistical analysis of hie (cold sensation) and hiesho (cold disorder) in kampo clinic. Evid Based Complement Alternat Med. 2013;2013:398458

12. Breiman L. Bagging predictors. Mach Learn. 1996;24(2):123-40.

13. Breiman L. Random forests. Mach Learn. 2001;45(1):5-32.

14. Hastie T, Tibshirani R, Friedman J. The elements of statistical learning, data mining, inference, and prediction. 2nd ed. New York: Springer; 2009. p. 587-604.

15. Caruana R, Niculescu-Mizil A. An empirical comparison of supervised learning algorithms. In: Proceedings of the 23rd International Conference on Machine learning. Pittsburgh, Pennsylvania: ACM; 2006. p. 161-8.

16. Shotton J, Sharp T, Kipman A, Fitzgibbon A, Finocchio M, Blake A, et al. Real-time human pose recognition in parts from single depth images. Commun ACM. 2013;56(1):116-14.

17. Gepshtein Y, Plotnikoff GA, Watanabe K. Kampo in women's health: Japan's traditional approach to premenstrual symptoms. J Altern Complement Med. 2008;14(4):427-35.

18. Furuya $Y$. Are pulse, tongue, and abdominal examination consistent across multiple doctors? Proposal for building the reliability and validity. J Kampo Med. 2009;56(8):1323-30.

19. Hastie T, Tibshirani R, Friedman J. The elements of statistical learning, data mining, inference, and prediction. 2nd ed. New York: Springer; 2009. p. 241-9.

20. Breiman L, Cutler A, Liaw A, Wiener M. Breiman and Cutler's random forests for classification and regression. 2014. https://www.stat.berkeley.edu/ breiman/RandomForests/. Accessed 13 Nov 2015.

21. Takakiwa M, Kim S, Ishino S, Hanawa T. Analysis of prescription in our clinic of Kampo medicine. Nippon Toyo lgaku Zasshi (Kampo Medicine). 2009;60(1):49-60

22. Igarashi N, Ito K, Kimura T, Akiba T, Irie S, Watanabe K, et al. The survey about Kampo administration of patients who visit Kampo clinic: Patient's recognition and compliance to Kampo medicine. Nippon Toyo Igaku Zasshi (Kampo Medicine). 2009;60(4):435-42.

23. Yoshino T, Katayama K, Munakata K, Horiba Y, Yamaguchi R, Imoto S, et al. Kampo traditional pattern diagnosis and the clustering analysis of patients with cold sensation. J Altern Complement Med. 2014;20(5):A47-A47.

24. Ishizuka M, Kita T, Katoh T, Tsuda M, Tosa H, Tsuneki H, et al. Cluster analysis of first-visit patients' answers for Japanese-Oriental Kampo questionnaire supporting the empirical decision of sho-syndrome. Nippon Toyo Igaku Zasshi (Kampo Medicine). 2004;55(3):347-54.

25. Zhang Q, Liu P, Zhang HW. Study on the patterns of TCM syndrome differentiation of 900 patients with posthepatitic cirrhosis. Zhongguo Zhong Xi Yi Jie He Za Zhi. 2006;26(8):694-7.

26. Wei HF, Liu T, Xing LJ, Zheng PY, Ji G. Distribution pattern of traditional Chinese medicine syndromes in 793 patients with fatty liver disease. Zhong Xi Yi Jie He Xue Bao. 2009:7(5):411-17.

27. Yakubo S, Ueda Y, Muroga K, Tanekura N, Okudaira T, Sasanuma T, et al. Modification of an abdominal diagnosis teaching simulator to reproduce patterns of resistance to pressure. Tradit Kampo Med. 2015;2(2):31-4.

28. Odaguchi H, Wakasugi A, Ito H, Shoda H, Gono Y, Kim S-J, et al. Statistical analysis of the findings in patients responded to goshuyuto. Nippon Toyo Igaku Zasshi (Kampo Medicine). 2007;58(6):1099-105.

29. Venables WN, Ripley BD. Modern applied statistics with S. New York: Springer; 2002.

30. Breiman L, Friedman JH, Olshen RA, Stone CJ. Classification and regression trees. Belmont: Wadsworth; 1983.

\section{Submit your next manuscript to BioMed Central and we will help you at every step:}

- We accept pre-submission inquiries

- Our selector tool helps you to find the most relevant journal

- We provide round the clock customer support

- Convenient online submission

- Thorough peer review

- Inclusion in PubMed and all major indexing services

- Maximum visibility for your research

Submit your manuscript at www.biomedcentral.com/submit
) Biomed Central 